\title{
Hybrid viscosity approximation methods for general systems of variational inequalities in Banach spaces
}

\author{
Abdul Latif ${ }^{*}$, Abdullah E Al-Mazrooei', Buthinah A Bin Dehaish ${ }^{1}$ and Jen C Yao ${ }^{1,2}$
}

"Correspondence: alatif@kau.edu.sa 'Department of Mathematics, King Abdulaziz University, P.O. Box 80203, Jeddah, 21589, Saudi Arabia Full list of author information is available at the end of the article

\begin{abstract}
Let $X$ be a uniformly convex and 2-uniformly smooth Banach space. In this paper, we propose an implicit iterative method and an explicit iterative method for solving a general system of variational inequalities (in short, GSVI) in X based on Korpelevich's extragradient method and viscosity approximation method. We show that the proposed algorithms converge strongly to some solutions of the GSVI under consideration. When $X$ is a 2-uniformly smooth Banach space with weakly sequentially continuous duality mapping, we also propose two methods, which were inspired and motivated by Korpelevich's extragradient method and Mann's iterative method. Furthermore, it is also proven that the proposed algorithms converge strongly to some solutions of the considered GSVI.
\end{abstract}

MSC: 49J30; 47H09; 47J20

Keywords: general system of variational inequalities; iterative methods; nonexpansive mapping; sunny nonexpansive retraction; fixed point; weakly sequentially continuous duality map; uniform smoothness

\section{Introduction}

Let $X$ be a real Banach space whose dual space is denoted by $X^{*}$. Let $U=\{x \in X:\|x\|=1\}$. A Banach space $X$ is said to be uniformly convex if for each $\epsilon \in(0,2]$, there exists $\delta>0$ such that for all $x, y \in U$,

$$
\|x-y\| \geq \epsilon \quad \Rightarrow \quad\|x+y\| / 2 \leq 1-\delta .
$$

It is known that a uniformly convex Banach space is reflexive and strict convex. A Banach space $X$ is said to be smooth if

$$
\lim _{t \rightarrow 0} \frac{\|x+t y\|-\|x\|}{t}
$$

exists for all $x, y \in U$. $X$ is said to be uniformly smooth if this limit is attained uniformly for $x, y \in U$. The norm of $X$ is said to be the Frechet differential if for each $x \in U$, this limit is attained uniformly for $y \in U$. Also, we define a function $\rho:[0, \infty) \rightarrow[0, \infty)$ called the modulus of smoothness of $X$ as follows:

$$
\rho(\tau)=\sup \left\{\frac{1}{2}(\|x+y\|+\|x-y\|)-1: x, y \in X,\|x\|=1,\|y\|=\tau\right\} .
$$

O2013 Latif et al.; licensee Springer. This is an Open Access article distributed under the terms of the Creative Commons Attribution License (http://creativecommons.org/licenses/by/2.0), which permits unrestricted use, distribution, and reproduction in any medium, provided the original work is properly cited. 
It is known that $X$ is uniformly smooth if and only if $\lim _{\tau \rightarrow 0} \rho(\tau) / \tau=0$. Let $q$ be a fixed real number with $1<q \leq 2$. Then a Banach space $X$ is said to be $q$-uniformly smooth if there exists a constant $c>0$ such that $\rho(\tau) \leq c \tau^{q}$ for all $\tau>0$.

Let $X^{*}$ be the dual of $X$. The normalized duality mapping $J: X \rightarrow 2^{X^{*}}$ is defined by

$$
J(x)=\left\{x^{*} \in X^{*}:\left\langle x, x^{*}\right\rangle=\|x\|^{2}=\left\|x^{*}\right\|^{2}\right\}, \quad \forall x \in X,
$$

where $\langle\cdot, \cdot\rangle$ denotes the generalized duality pairing. It is an immediate consequence of the Hahn-Banach theorem that $J(x)$ is nonempty for each $x \in X$. Moreover, it is known that $J$ is single-valued if and only if $X$ is smooth, whereas if $X$ is uniformly smooth, then the mapping $J$ is uniformly continuous on bounded subsets of $X$. Let $C$ be a nonempty closed convex subset of a real Banach space $X$. A mapping $T: C \rightarrow C$ is called nonexpansive if

$$
\|T x-T y\| \leq\|x-y\|, \quad \forall x, y \in C .
$$

We use the notation $\rightarrow$ to indicate the weak convergence and the one $\rightarrow$ to indicate the strong convergence.

Definition 1.1 Let $A: C \rightarrow X$ be a mapping of $C$ into $X$. Then $A$ is said to be

(i) accretive if for each $x, y \in C$ there exists $j(x-y) \in J(x-y)$ such that

$$
\langle A x-A y, j(x-y)\rangle \geq 0
$$

where $J$ is the normalized duality mapping;

(ii) $\alpha$-strongly accretive if for each $x, y \in C$ there exists $j(x-y) \in J(x-y)$ such that

$$
\langle A x-A y, j(x-y)\rangle \geq \alpha\|x-y\|^{2}
$$

for some $\alpha \in(0,1)$;

(iii) $\beta$-inverse-strongly accretive if for each $x, y \in C$, there exists $j(x-y) \in J(x-y)$ such that

$$
\langle A x-A y, j(x-y)\rangle \geq \beta\|A x-A y\|^{2}
$$

for some $\beta>0$;

(iv) $\lambda$-strictly pseudocontractive if for each $x, y \in C$, there exists $j(x-y) \in J(x-y)$ such that

$$
\langle A x-A y, j(x-y)\rangle \leq\|x-y\|^{2}-\lambda\|x-y-(A x-A y)\|^{2}
$$

for some $\lambda \in(0,1)$.

Very recently, Yao et al. [1] studied the following general system of variational inequalities (GSVI) in a real smooth Banach space $X$, which is to find $\left(x^{*}, y^{*}\right) \in C \times C$ such that

$$
\begin{cases}\left\langle\mu_{1} B_{1} y^{*}+x^{*}-y^{*}, J\left(x-x^{*}\right)\right\rangle \geq 0, & \forall x \in C, \\ \left\langle\mu_{2} B_{2} x^{*}+y^{*}-x^{*}, J\left(x-y^{*}\right)\right\rangle \geq 0, & \forall x \in C,\end{cases}
$$


where $C$ is a nonempty, closed and convex subset of $X, B_{1}, B_{2}: C \rightarrow X$ are two nonlinear mappings, and $\mu_{1}$ and $\mu_{2}$ are two positive constants. The set of solutions of GSVI (1.1) is denoted by $\operatorname{GSVI}\left(C, B_{1}, B_{2}\right)$. In particular, if $X=H$, a real Hilbert space, then GSVI (1.1) reduces to the following GSVI of finding $\left(x^{*}, y^{*}\right) \in C \times C$ such that

$$
\begin{cases}\left\langle\mu_{1} B_{1} y^{*}+x^{*}-y^{*}, x-x^{*}\right\rangle \geq 0, & \forall x \in C, \\ \left\langle\mu_{2} B_{2} x^{*}+y^{*}-x^{*}, x-y^{*}\right\rangle \geq 0, & \forall x \in C,\end{cases}
$$

which was considered by Ceng et al. [2]. The set of solutions of problem (1.2) is also denoted by $\operatorname{GSVI}\left(C, B_{1}, B_{2}\right)$. In [2], problem (1.2) was transformed into a fixed point problem in the following way.

Lemma 1.1 (See [2]) For given $\bar{x}, \bar{y} \in C,(\bar{x}, \bar{y})$ is a solution of problem (1.2) if and only if $\bar{x}$ is a fixed point of the mapping $G: C \rightarrow C$ defined by

$$
G(x)=P_{C}\left[P_{C}\left(x-\mu_{2} B_{2} x\right)-\mu_{1} B_{1} P_{C}\left(x-\mu_{2} B_{2} x\right)\right], \quad \forall x \in C,
$$

where $\bar{y}=P_{C}\left(\bar{x}-\mu_{2} B_{2} \bar{x}\right)$.

In this paper, we continue to study problem GSVI (1.1). We propose implicit and explicit algorithms based on Korpelevich's extragradient method [3], viscosity approximation method [4] and Mann's iterative method [5] to find approximate solutions of GSVI (1.1). Strong convergence results of these methods will be established under very mild conditions. We observe that some recent results in this direction have been obtained in, e.g., [6-10] and the references therein.

\section{Preliminaries}

We need the following lemmas that will be used in the sequel.

Lemma 2.1 (See [11]) Let $\left\{s_{n}\right\}$ be a sequence of nonnegative real numbers satisfying

$$
s_{n+1} \leq\left(1-\alpha_{n}\right) s_{n}+\alpha_{n} \beta_{n}+\gamma_{n}, \quad \forall n \geq 0,
$$

where $\left\{\alpha_{n}\right\},\left\{\beta_{n}\right\}$ and $\left\{\gamma_{n}\right\}$ satisfy the conditions:

(i) $\left\{\alpha_{n}\right\} \subset[0,1], \sum_{n=0}^{\infty} \alpha_{n}=\infty$;

(ii) $\limsup _{n \rightarrow \infty} \beta_{n} \leq 0$;

(iii) $\gamma_{n} \geq 0(\forall n \geq 0), \sum_{n=0}^{\infty} \gamma_{n}<\infty$.

Then $\lim \sup _{n \rightarrow \infty} s_{n}=0$.

Lemma 2.2 (See [11]) In a smooth Banach space X, the following inequality holds:

$$
\|x+y\|^{2} \leq\|x\|^{2}+2\langle y, J(x+y)\rangle, \quad \forall x, y \in X
$$

Let LIM be a continuous linear functional on $l^{\infty}$ and $\left(a_{0}, a_{1}, \ldots\right) \in l^{\infty}$. We write $\operatorname{LIM} a_{n}$ instead of $\operatorname{LIM}\left(\left(a_{0}, a_{1}, \ldots\right)\right)$. LIM is said to be a Banach limit if LIM satisfies $\|\operatorname{LIM}\|=$ $\operatorname{LIM} 1=1$, and $\operatorname{LIM} a_{n+1}=\operatorname{LIM} a_{n}$ for all $\left(a_{0}, a_{1}, \ldots\right) \in l^{\infty}$. It is well known that for the Banach limit LIM, the following hold: 
(i) for all $n \geq 1, a_{n} \leq c_{n}$ implies that $\operatorname{LIM} a_{n} \leq \operatorname{LIM} c_{n}$;

(ii) $\operatorname{LIM} a_{n+N}=\operatorname{LIM} a_{n}$ for any fixed positive integer $N$;

(iii) $\liminf _{n \rightarrow \infty} a_{n} \leq \operatorname{LIM} a_{n} \leq \limsup \sup _{n \rightarrow \infty} a_{n}$ for all $\left(a_{0}, a_{1}, \ldots\right) \in l^{\infty}$.

Lemma 2.3 (See [4]) Let $\left(a_{0}, a_{1}, \ldots\right) \in l^{\infty}$. If $\operatorname{LIM} a_{n}=0$, then there exists a subsequence $\left\{a_{n_{k}}\right\}$ of $\left\{a_{n}\right\}$ such that $a_{n_{k}} \rightarrow 0$ as $k \rightarrow \infty$.

We also need the following lemmas for the proofs of our main results.

Lemma 2.4 (See [12]) Let $q$ be a given real number with $1<q \leq 2$, and let $X$ be a $q$-uniformly smooth Banach space. Then

$$
\|x+y\|^{q} \leq\|x\|^{q}+q\left\langle y, J_{q}(x)\right)+2\|\kappa y\|^{q}, \quad \forall x, y \in X,
$$

where $\kappa$ is the q-uniformly smooth constant of $X$, and $J_{q}$ is the generalized duality mapping from $X$ into $2^{X^{*}}$ defined by

$$
J_{q}(x)=\left\{x^{*} \in X^{*}:\left\langle x, x^{*}\right\rangle=\|x\|^{q},\left\|x^{*}\right\|=\|x\|^{q-1}\right\}, \quad \forall x \in X .
$$

Let $D$ be a subset of $C$, and let $\Pi$ be a mapping of $C$ into $D$. Then $\Pi$ is said to be sunny if

$$
\Pi[\Pi(x)+t(x-\Pi(x))]=\Pi(x)
$$

whenever $\Pi(x)+t(x-\Pi(x)) \in C$ for $x \in C$ and $t \geq 0$. A mapping $\Pi$ of $C$ into itself is called a retraction if $\Pi^{2}=\Pi$. If a mapping $\Pi$ of $C$ into itself is a retraction, then $\Pi(z)=z$ for every $z \in R(\Pi)$, where $R(\Pi)$ is the range of $\Pi$. A subset $D$ of $C$ is called a sunny nonexpansive retract of $C$ if there exists a sunny nonexpansive retraction from $C$ onto $D$. The following lemma concerns the sunny nonexpansive retraction.

Lemma 2.5 (See [13]) Let C be a nonempty closed convex subset of a real smooth Banach space $X$, let $D$ be a nonempty subset of $C$, and let $\Pi$ be a retraction from $C$ onto $D$. Then $\Pi$ is sunny and nonexpansive if and only if

$$
\langle x-\Pi(x), J(y-\Pi(x))\rangle \leq 0
$$

for all $x \in C$ and $y \in D$.

It is well known that if $X=H$ a Hilbert space, then a sunny nonexpansive retraction $\Pi_{C}$ is coincident with the metric projection from $X$ onto $C$; that is, $\Pi_{C}=P_{C}$. Let $C$ be a nonempty closed convex subset of a uniformly convex and uniformly smooth Banach space $X$, and let $T: C \rightarrow C$ be a nonexpansive mapping with the fixed point set $\operatorname{Fix}(T) \neq \emptyset$. Then the set $\operatorname{Fix}(T)$ is a sunny nonexpansive retract of $C$.

Lemma 2.6 (Demiclosedness principle; see [14]) Let X be a uniformly convex Banach space or a reflexive Banach space satisfying Opial's condition, let $C$ be a nonempty closed convex subset of $X$, and let $T: C \rightarrow C$ be a nonexpansive mapping. Then the mapping $I-T$ 
is demiclosed on $C$, where $I$ is the identity mapping; that is, if $\left\{x_{n}\right\}$ is a sequence of $C$ such that $x_{n} \rightarrow x$ and $(I-T) x_{n} \rightarrow y$, then $(I-T) x=y$.

Lemma 2.7 (See [15]) Let $\left\{x_{n}\right\}$ and $\left\{z_{n}\right\}$ be bounded sequences in a Banach space $X$, and let $\left\{\alpha_{n}\right\}$ be a sequence in $[0,1]$, which satisfies the following condition

$$
0<\liminf _{n \rightarrow \infty} \alpha_{n} \leq \limsup _{n \rightarrow \infty} \alpha_{n}<1
$$

Suppose that $x_{n+1}=\alpha_{n} x_{n}+\left(1-\alpha_{n}\right) z_{n}, \forall n \geq 0$ and $\lim \sup _{n \rightarrow \infty}\left(\left\|z_{n+1}-z_{n}\right\|-\left\|x_{n+1}-x_{n}\right\|\right) \leq 0$. Then $\lim _{n \rightarrow \infty}\left\|z_{n}-x_{n}\right\|=0$.

Lemma 2.8 (See [1]) Let $C$ be a nonempty closed convex subset of a real smooth Banach space $X$. Assume that the mapping $F: C \rightarrow X$ is accretive and weakly continuous along segments (i.e., $F(x+t y) \rightarrow F(x)$ as $t \rightarrow 0)$. Then the variational inequality

$$
\text { find } \tilde{x} \in C: \quad\langle F(\tilde{x}), J(x-\tilde{x})| \geq 0, \quad \forall x \in C,
$$

is equivalent to the dual variational inequality

$$
\text { find } \tilde{x} \in C: \quad\langle F(x), J(x-\tilde{x})| \geq 0, \quad \forall x \in C .
$$

Lemma 2.9 (See [1]) Let $C$ be a nonempty closed convex subset of a 2-uniformly smooth Banach space $X$. Let the mapping $B_{i}: C \rightarrow X$ be $\alpha_{i}$-inverse-strongly accretive for $i=1,2$. Then we have

$$
\left\|\left(I-\mu_{i} B_{i}\right) x-\left(I-\mu_{i} B_{i}\right) y\right\|^{2} \leq\|x-y\|^{2}+2 \lambda_{i}\left(\kappa^{2} \lambda_{i}-\alpha_{i}\right)\left\|B_{i} x-B_{i} y\right\|^{2}, \quad \forall x, y \in C
$$

for $i=1$, 2. In particular, if $0 \leq \mu_{i} \leq \frac{\alpha_{i}}{\kappa^{2}}$, then $I-\mu_{i} B_{i}$ is nonexpansive for $i=1,2$.

Lemma 2.10 (See [1]) Let $C$ be a nonempty closed convex subset of a real 2-uniformly smooth Banach space $X$. Let $\Pi_{C}$ be a sunny nonexpansive retraction from $X$ onto $C$. Let the mapping $B_{i}: C \rightarrow X$ be $\alpha_{i}$-inverse-strongly accretive for $i=1$, 2. Let $G: C \rightarrow C$ be the mapping defined by (1.3). If $0<\mu_{i} \leq \frac{\alpha_{i}}{\kappa^{2}}$, then $G: C \rightarrow C$ is nonexpansive for $i=1,2$.

\section{Implicit iterative schemes}

In this section, we propose implicit iterative schemes and show the strong convergence theorems. First, we state the following obvious proposition.

Proposition 3.1 Let $C$ be a nonempty closed convex subset of a real smooth Banach space $X$, and let $F: C \rightarrow X$ be a mapping.

(i) If $F: C \rightarrow X$ is $\alpha$-strongly accretive and $\lambda$-strictly pseudocontractive with $\alpha+\lambda \geq 1$, then $I-F$ is nonexpansive, and $F$ is Lipschitz-continuous with constant $1+\frac{1}{\lambda}$;

(ii) If $F: C \rightarrow X$ is $\alpha$-strongly accretive and $\lambda$-strictly pseudocontractive with $\alpha+\lambda \geq 1$, then for any fixed $\tau \in(0,1), I-\tau F$ is a contraction with coefficient $1-\tau\left(1-\sqrt{\frac{1-\alpha}{\lambda}}\right)$. 
Lemma 3.1 Let $C$ be a nonempty closed convex subset of a real smooth Banach space $X$. Let $\Pi_{C}$ be a sunny nonexpansive retraction from $X$ onto $C$, and let the mapping $B_{i}: C \rightarrow X$ be $\alpha_{i}$-inverse-strongly accretive for $i=1,2$. For given $x^{*}, y^{*} \in C,\left(x^{*}, y^{*}\right)$ is a solution of GSVI (1.1) if and only if $x^{*}=\Pi_{C}\left(y^{*}-\mu_{1} B_{1} y^{*}\right)$, where $y^{*}=\Pi_{C}\left(x^{*}-\mu_{2} B_{2} x^{*}\right)$.

Proof Rewriting GSVI (1.1) as

$$
\begin{cases}\left\langle x^{*}-\left(y^{*}-\mu_{1} B_{1} y^{*}\right), J\left(x-x^{*}\right)\right\rangle \geq 0, & \forall x \in C, \\ \left\langle y^{*}-\left(x^{*}-\mu_{2} B_{2} x^{*}\right), J\left(x-y^{*}\right)\right\rangle \geq 0, & \forall x \in C,\end{cases}
$$

the proof then follows from Lemma 2.4.

By Lemma 3.1, we observe that

$$
x^{*}=\Pi_{C}\left[\Pi_{C}\left(x^{*}-\mu_{2} B_{2} x^{*}\right)-\mu_{1} B_{1} \Pi_{C}\left(x^{*}-\mu_{2} B_{2} x^{*}\right)\right],
$$

which implies that $x^{*}$ is a fixed point of the mapping $G$. Throughout this paper, the set of fixed points of the mapping $G$ is denoted by $\Omega$.

To solve GSVI (1.1), we first propose an implicit algorithm as follows. Let $C$ be a nonempty closed convex subset of a real 2-uniformly smooth Banach space $X$. Let $\Pi_{C}$ be a sunny nonexpansive retraction from $X$ onto $C$. As previously, let $\Xi_{C}$ be the set of all contractions on $C$. Let the mapping $B_{i}: C \rightarrow X$ be $\alpha_{i}$-inverse-strongly accretive for $i=1,2$. Let $f \in \Xi_{C}$ with coefficient $\rho \in(0,1)$ and $F: C \rightarrow X$ be $\alpha$-strongly accretive and $\lambda$-strictly pseudocontractive with $\alpha+\lambda \geq 1$. In what follows, we assume that $0<\mu_{i} \leq \frac{\alpha_{i}}{\kappa^{2}}$ for $i=1,2$. For any given $t \in(0,1)$, we define a mapping $T_{t}: C \rightarrow C$ by

$$
T_{t} x=t f\left(x_{t}\right)+(1-t) \Pi_{C}\left(I-\theta_{t} F\right) \Pi_{C}\left(I-\mu_{1} B_{1}\right) \Pi_{C}\left(I-\mu_{2} B_{2}\right) x, \quad \forall x \in C,
$$

where $\theta_{t} \in[0,1), \forall t \in(0,1)$.

Define another mapping $S_{t}$ :

$$
\begin{aligned}
S_{t} x & =\Pi_{C}\left(I-\theta_{t} F\right) \Pi_{C}\left(I-\mu_{1} B_{1}\right) \Pi_{C}\left(I-\mu_{2} B_{2}\right) x \\
& =\Pi_{C}\left[\left(1-\theta_{t}\right) I+\theta_{t}(I-F)\right] \Pi_{C}\left(I-\mu_{1} B_{1}\right) \Pi_{C}\left(I-\mu_{2} B_{2}\right) x, \quad \forall x \in C .
\end{aligned}
$$

Then $T_{t}$ is rewritten as

$$
T_{t} x=t f\left(x_{t}\right)+(1-t) S_{t} x, \quad \forall x \in C .
$$

Let us show that $S_{t}: C \rightarrow C$ is nonexpansive. As a matter of fact, since $\alpha+\lambda \geq 1$, by Proposition 3.1 we know that $I-F$ is nonexpansive; that is,

$$
\|(I-F) x-(I-F) y\| \leq\|x-y\|, \quad \forall x, y \in C .
$$

Hence, $I-\theta_{t} F=\left(1-\theta_{t}\right) I+\theta_{t}(I-F)$ is nonexpansive. So, $\Pi_{C}\left(I-\theta_{t} F\right)$ is nonexpansive. We note that by Lemma 2.9, $\Pi_{C}\left(I-\mu_{i} B_{i}\right)$ is nonexpansive for $i=1$, 2 . Thus, it follows from 
(3.3) that $S_{t}: C \rightarrow C$ is nonexpansive. This together with (3.4) implies that for all $x, y \in C$,

$$
\begin{aligned}
\left\|T_{t} x-T_{t} y\right\| & =\left\|t(f(x)-f(y))+(1-t)\left(S_{t} x-S_{t} y\right)\right\| \\
& \leq t\|f(x)-f(y)\|+(1-t)\left\|S_{t} x-S_{t} y\right\| \\
& \leq t \rho\|x-y\|+(1-t)\|x-y\| \\
& =(1-t(1-\rho))\|x-y\| .
\end{aligned}
$$

So, $T_{t}: C \rightarrow C$ is a contraction. Therefore, the Banach contraction principle guarantees that $T_{t}$ has a unique fixed point in $C$, which we denote by $x_{t}$; that is,

$$
x_{t}=t f\left(x_{t}\right)+(1-t) S_{t} x_{t}=t f\left(x_{t}\right)+(1-t) \Pi_{C}\left(I-\theta_{t} F\right) \Pi_{C}\left(I-\mu_{1} B_{1}\right) \Pi_{C}\left(I-\mu_{2} B_{2}\right) x_{t} .
$$

We now state and prove our first main result.

Theorem 3.1 Let $C$ be a nonempty closed convex subset of a real 2-uniformly smooth Banach space $X$. Let $\Pi_{C}$ be a sunny nonexpansive retraction from $X$ onto $C$. Let the mapping $B_{i}: C \rightarrow X$ be $\alpha_{i}$-inverse-strongly accretive for $i=1,2$. Let $f \in \Xi_{C}$ with coefficient $\rho \in(0,1)$, and let $F: C \rightarrow X$ be $\alpha$-strongly accretive and $\lambda$-strictly pseudocontractive with $\alpha+\lambda \geq 1$. Assume that $0<\mu_{i} \leq \frac{\alpha_{i}}{\kappa^{2}}$ for $i=1,2$. Let $x_{t} \in C$ be the unique solution in $C$ to Equation (3.5), where $\theta_{t} \in[0,1), \forall t \in(0,1)$ and $\lim _{t \rightarrow 0^{+}} \theta_{t} / t=0$. Then $\Omega \neq \emptyset$ if and only if

$$
\limsup _{t \rightarrow 0^{+}}\left\|x_{t}\right\|<\infty
$$

and in this case, $\left\{x_{t}\right\}$ converges as $t \rightarrow 0^{+}$strongly to an element of $\Omega$. In addition, if we define $Q: \Xi_{C} \rightarrow \Omega$ by

$$
Q(f):=s-\lim _{t \rightarrow 0} x_{t}, \quad \forall f \in \Xi_{C}
$$

then $Q(f)$ solves the variational inequality problem (VIP)

$$
\langle(I-f) Q(f), J(Q(f)-p)\rangle \leq 0, \quad \forall f \in \Xi_{C}, p \in \Omega .
$$

In particular, if $f=u \in C$ is a constant, then (3.7) reduces to the sunny nonexpansive retraction of Reich from $C$ onto $\Omega$,

$$
\langle Q(u)-u, J(Q(u)-p)\rangle \leq 0, \quad \forall u \in C, p \in \Omega
$$

Proof If $\Omega \neq \emptyset$, we can take $p \in \Omega$ to derive from (3.5) that for $t \in(0,1)$,

$$
\begin{aligned}
\left\|x_{t}-p\right\| \leq & t\left\|f\left(x_{t}\right)-p\right\|+(1-t)\left\|S_{t} x_{t}-p\right\| \\
\leq & t\left(\left\|f\left(x_{t}\right)-f(p)\right\|+\|f(p)-p\|\right)+(1-t)\left(\left\|S_{t} x_{t}-S_{t} p\right\|+\left\|S_{t} p-p\right\|\right) \\
= & t\left(\left\|f\left(x_{t}\right)-f(p)\right\|+\|f(p)-p\|\right) \\
& +(1-t)\left(\left\|S_{t} x_{t}-S_{t} p\right\|+\left\|\Pi_{C}\left(I-\theta_{t} F\right) p-\Pi_{C} p\right\|\right)
\end{aligned}
$$




$$
\begin{aligned}
& \leq t \rho\left\|x_{t}-p\right\|+t\|f(p)-p\|+(1-t)\left(\left\|x_{t}-p\right\|+\theta_{t}\|F(p)\|\right) \\
& =(1-t(1-\rho))\left\|x_{t}-p\right\|+t\|f(p)-p\|+(1-t) \theta_{t}\|F(p)\| \\
& \leq t\|f(p)-p\|+(1-t(1-\rho))\left\|x_{t}-p\right\|+\theta_{t}\|F(p)\|,
\end{aligned}
$$

which implies that

$$
\left\|x_{t}-p\right\| \leq \frac{1}{1-\rho}\|f(p)-p\|+\frac{\theta_{t}}{t} \cdot \frac{\|F(p)\|}{1-\rho} .
$$

Because $\lim _{t \rightarrow 0^{+}} \theta_{t} / t=0$, we deduce that

$$
\limsup _{t \rightarrow 0^{+}}\left\|x_{t}\right\| \leq\|p\|+\frac{1}{1-\rho}\|f(p)-p\|<\infty,
$$

and hence, (3.6) holds.

Conversely, assume (3.6); that is, $\left\{x_{t}\right\}$ remains bounded when $t \rightarrow 0^{+}$; hence, $f\left(x_{t}\right)$ and $F\left(G\left(x_{t}\right)\right)$ are bounded when $t \rightarrow 0^{+}$, where $G$ is defined by (1.3). Because in terms of (3.5),

$$
x_{t}-G\left(x_{t}\right)=\frac{t}{1-t}\left(f\left(x_{t}\right)-x_{t}\right)+S_{t} x_{t}-G\left(x_{t}\right),
$$

we obtain

$$
\begin{aligned}
\left\|x_{t}-G\left(x_{t}\right)\right\| & \leq \frac{t}{1-t}\left\|f\left(x_{t}\right)-x_{t}\right\|+\left\|S_{t} x_{t}-G\left(x_{t}\right)\right\| \\
& =\frac{t}{1-t}\left\|f\left(x_{t}\right)-x_{t}\right\|+\left\|\Pi_{C}\left(G\left(x_{t}\right)-\theta_{t} F\left(G\left(x_{t}\right)\right)\right)-\Pi_{C} G\left(x_{t}\right)\right\| \\
& \leq \frac{t}{1-t}\left\|f\left(x_{t}\right)-x_{t}\right\|+\theta_{t}\left\|F\left(G\left(x_{t}\right)\right)\right\|,
\end{aligned}
$$

which hence yields

$$
\lim _{t \rightarrow 0^{+}}\left\|x_{t}-G\left(x_{t}\right)\right\|=0
$$

Now, assume that $t_{n} \rightarrow 0^{+}$. Since $\left\{x_{t}\right\}$ remains bounded as $t \rightarrow 0^{+}$. Set $x_{n}:=x_{t_{n}}$. Then $\left\{x_{n}\right\}$ is bounded. Now, define $g: C \rightarrow[0, \infty)$ by

$$
g(x)=\operatorname{LIM}\left\|x_{n}-x\right\|^{2}, \quad \forall x \in C,
$$

where LIM is a Banach limit on $l^{\infty}$. Let

$$
K=\left\{x \in C: g(x)=\min _{y \in C} \operatorname{LIM}\left\|x_{n}-y\right\|^{2}\right\} .
$$

It is easily seen that $K$ is nonempty closed convex bounded subset of $X$. Since (note that $\left.\left\|x_{n}-G\left(x_{n}\right)\right\| \rightarrow 0\right)$

$$
\begin{aligned}
g(G(x)) & =\operatorname{LIM}\left\|x_{n}-G(x)\right\|^{2} \\
& =\operatorname{LIM}\left\|G\left(x_{n}\right)-G\left(x_{n}\right)\right\|^{2} \\
& \leq \operatorname{LIM}\left\|x_{n}-x\right\|^{2}=g(x),
\end{aligned}
$$


it follows that $G(K) \subset K$; that is, $K$ is invariant under $G$. Since a uniformly smooth Banach space has the fixed point property for nonexpansive mappings, $G$ has a fixed point, say $z$, in $K$. Since $z$ is also a minimizer of $g$ over $C$, it follows that, for $t \in(0,1)$ and $x \in C$,

$$
0 \leq \frac{g(z+t(x-z))-g(z)}{t}=\operatorname{LIM} \frac{\left\|\left(x_{n}-z\right)+t(z-x)\right\|^{2}-\left\|x_{n}-z\right\|^{2}}{t} .
$$

The uniform smoothness of $X$ implies that the duality map $J$ is norm-to-norm uniformly continuous on bounded sets of $X$. Letting $t \rightarrow 0$, we find that the two limits above can be interchanged and obtain

$$
\operatorname{LIM}\left\langle x-z, J\left(x_{n}-z\right)\right\rangle \leq 0, \quad \forall x \in C
$$

Since

$$
\begin{aligned}
x_{t}-z=t & \left(f\left(x_{t}\right)-z\right)+(1-t)\left(S_{t} x_{t}-z\right), \\
\left\|x_{t}-z\right\|^{2}= & t\left\{f\left(x_{t}\right)-z, J\left(x_{t}-z\right)\right\rangle+(1-t)\left\langle S_{t} x_{t}-z, J\left(x_{t}-z\right)\right\rangle \\
\leq & t\left\langle f\left(x_{t}\right)-z, J\left(x_{t}-z\right)\right\rangle+(1-t)\left\|S_{t} x_{t}-z\right\|\left\|x_{t}-z\right\| \\
\leq & t\left\langle f\left(x_{t}\right)-z, J\left(x_{t}-z\right)\right\rangle+(1-t)\left(\left\|S_{t} x_{t}-S_{t} z\right\|+\left\|S_{t} z-z\right\|\right)\left\|x_{t}-z\right\| \\
= & t\left\langle f\left(x_{t}\right)-z, J\left(x_{t}-z\right)\right\rangle \\
& +(1-t)\left(\left\|S_{t} x_{t}-S_{t} z\right\|+\left\|\Pi_{C}\left(I-\theta_{t} F\right) z-\Pi_{C} z\right\|\right)\left\|x_{t}-z\right\| \\
\leq & t\left\langle f\left(x_{t}\right)-z, J\left(x_{t}-z\right)\right\rangle+(1-t)\left(\left\|x_{t}-z\right\|+\theta_{t}\|F(z)\|\right)\left\|x_{t}-z\right\| \\
\leq & t\left\langle f\left(x_{t}\right)-z, J\left(x_{t}-z\right)\right\rangle+(1-t)\left\|x_{t}-z\right\|^{2}+\theta_{t}\|F(z)\|\left\|x_{t}-z\right\| .
\end{aligned}
$$

Hence,

$$
\begin{aligned}
\left\|x_{t}-z\right\|^{2} & \leq\left\langle f\left(x_{t}\right)-z, J\left(x_{t}-z\right)\right\rangle+\frac{\theta_{t}}{t}\|F(z)\|\left\|x_{t}-z\right\| \\
& =\left\langle f\left(x_{t}\right)-x, J\left(x_{t}-z\right)\right\rangle+\left\langle x-z, J\left(x_{t}-z\right)\right\rangle+\frac{\theta_{t}}{t}\|F(z)\|\left\|x_{t}-z\right\| .
\end{aligned}
$$

So by (3.11), for $x \in C$,

$$
\begin{aligned}
\operatorname{LIM}\left\|x_{n}-z\right\|^{2} & \leq \operatorname{LIM}\left\langle f\left(x_{n}\right)-x, J\left(x_{n}-z\right)\right\rangle+\operatorname{LIM}\left\langle x-z, J\left(x_{n}-z\right)\right\rangle \\
& \leq \operatorname{LIM}\left\langle f\left(x_{n}\right)-x, J\left(x_{n}-z\right)\right\rangle \\
& \leq \operatorname{LIM}\left\|f\left(x_{n}\right)-x\right\|\left\|x_{n}-z\right\| .
\end{aligned}
$$

In particular,

$$
\operatorname{LIM}\left\|x_{n}-z\right\|^{2} \leq \operatorname{LIM}\left\|f\left(x_{n}\right)-f(z)\right\|\left\|x_{n}-z\right\| \leq \rho\left\|x_{n}-z\right\|^{2} .
$$

Thus,

$$
\operatorname{LIM}\left\|x_{n}-z\right\|^{2}=0
$$

and there exists a subsequence which is still denoted by $\left\{x_{n}\right\}$ such that $x_{n} \rightarrow z$. 
Now, assume that there exists another subsequence $\left\{x_{m}\right\}$ of $\left\{x_{t}\right\}$ such that $x_{m} \rightarrow \bar{z} \in \Omega$. It follows from (3.12) that

$$
\|\bar{z}-z\|^{2} \leq\langle f(\bar{z})-z, J(\bar{z}-z)\rangle .
$$

Interchange $\bar{q}$ and $q$ to obtain

$$
\|z-\bar{z}\|^{2} \leq\langle f(z)-\bar{z}, J(z-\bar{z})\rangle
$$

Adding up (3.13) and (3.14) yields

$$
\begin{aligned}
2\|\bar{z}-z\|^{2} & \leq\langle f(\bar{z})-f(z), J(\bar{z}-z)\rangle+\langle\bar{z}-z, J(\bar{z}-z)\rangle \\
& \leq(1+\rho)\|\bar{z}-z\|^{2} .
\end{aligned}
$$

Since $\rho \in(0,1)$, this implies that $\bar{z}=z$. Therefore, $x_{t} \rightarrow z$ as $t \rightarrow 0$.

Define $Q: \Xi_{C} \rightarrow \Omega$ by

$$
Q(f):=s-\lim _{t \rightarrow 0} x_{t}
$$

Since $x_{t}=t f\left(x_{t}\right)+(1-t) S_{t} x_{t}$, we have

$$
(I-f) x_{t}=-\frac{1-t}{t}\left(x_{t}-G\left(x_{t}\right)+G\left(x_{t}\right)-S_{t} x_{t}\right) .
$$

Hence, for $p \in \Omega$,

$$
\begin{aligned}
\left\langle(I-f) x_{t}, J\left(x_{t}-p\right)\right\rangle= & -\frac{1-t}{t}\left\langle(I-G) x_{t}-(I-G) p, J\left(x_{t}-p\right)\right\rangle \\
& -\frac{1-t}{t}\left\langle G\left(x_{t}\right)-S_{t} x_{t}, J\left(x_{t}-p\right)\right\rangle \\
\leq & \frac{1-t}{t}\left\|G\left(x_{t}\right)-S_{t} x_{t}\right\| \varphi\left(\left\|x_{t}-p\right\|\right) \\
& =\frac{1-t}{t}\left\|\Pi_{C} G\left(x_{t}\right)-\Pi_{C}\left(I-\theta_{t} F\right) G\left(x_{t}\right)\right\| \varphi\left(\left\|x_{t}-p\right\|\right) \\
& \leq \frac{\theta_{t}}{t}\left\|F\left(G\left(x_{t}\right)\right)\right\|\left\|x_{t}-p\right\| .
\end{aligned}
$$

Because $\theta_{t} / t \rightarrow 0$ and $x_{t} \rightarrow Q(f)$ as $t \rightarrow 0^{+}$, taking the limit as $t \rightarrow 0^{+}$in (3.17), we obtain that

$$
\langle(I-f) Q(f), J(Q(f)-p)\rangle \leq 0 .
$$

If $f(x)=u(\forall x \in C)$ is a constant, then

$$
\langle Q(u)-u, J(Q(u)-p)\rangle \leq 0 .
$$

Hence, $Q$ reduces to the sunny nonexpansive retraction from $C$ to $\Omega$. 
Theorem 3.2 Let C be a nonempty closed convex subset of a 2-uniformly smooth Banach space $X$ with weakly sequentially continuous duality mapping $J$. Let $\Pi_{C}$ be a sunny nonexpansive retraction from $X$ onto $C$. Let the mapping $B_{i}: C \rightarrow X$ be $\alpha_{i}$-inverse-strongly accretive with $0 \leq \mu_{i} \leq \frac{\alpha_{i}}{\kappa^{2}}$ for $i=1,2$. Let $F: C \rightarrow X$ be $\alpha$-strongly accretive and $\lambda$-strictly pseudocontractive with $\alpha+\lambda>1$. Assume that $\Omega \neq \emptyset$. Let the net $\left\{x_{t}\right\}$ be defined by the implicit scheme

$$
x_{t}=\Pi_{C}(I-t F) \Pi_{C}\left(I-\mu_{1} B_{1}\right) \Pi_{C}\left(I-\mu_{2} B_{2}\right) x_{t}, \quad \forall t \in(0,1) .
$$

Then $\left\{x_{t}\right\}$ converges in norm, as $t \rightarrow 0^{+}$, to the unique solution of the VIP

$$
\text { find } \tilde{x} \in \Omega: \quad\langle F(\tilde{x}), J(x-\tilde{x})| \geq 0, \quad \forall x \in \Omega .
$$

Proof For any given $t \in(0,1)$, consider the following mapping

$$
W_{t} x:=\Pi_{C}(I-t F) \Pi_{C}\left(I-\mu_{1} B_{1}\right) \Pi_{C}\left(I-\mu_{2} B_{2}\right) x, \quad \forall x \in C .
$$

By Proposition 3.1(ii) and Lemma 2.9, we know that $\Pi_{C}\left(I-\mu_{i} B_{i}\right)$ is nonexpansive for $i=$ 1,2 , and $I-t F$ is contractive with coefficient $1-t\left(1-\sqrt{\frac{1-\alpha}{\lambda}}\right)$. Hence,

$$
\left\|W_{t} x-W_{t} y\right\| \leq\left(1-t\left(1-\sqrt{\frac{1-\alpha}{\lambda}}\right)\right)\|x-y\|, \quad \forall x, y \in C
$$

This means that $W_{t}$ is a contraction. Therefore, the Banach contraction principle guarantees that $W_{t}$ has a unique fixed point in $C$, which we denote by $x_{t}$. This shows that the implicit scheme (3.20) is well defined.

Now, we show that $\left\{x_{t}\right\}$ is bounded. As a matter of fact, take $p \in \Omega$ arbitrarily. Then it follows from (3.20) and Lemma 3.1 that

$$
\begin{aligned}
\left\|x_{t}-p\right\| & =\left\|\Pi_{C}(I-t F) G\left(x_{t}\right)-\Pi_{C}(I-t F) G(p)+\Pi_{C}(I-t F) G(p)-p\right\| \\
& \leq\left\|\Pi_{C}(I-t F) G\left(x_{t}\right)-\Pi_{C}(I-t F) G(p)\right\|+\left\|\Pi_{C}(I-t F) p-\Pi_{C} p\right\| \\
& =\left\|W_{t} x_{t}-W_{t} p\right\|+\left\|\Pi_{C}(I-t F) p-\Pi_{C} p\right\| \\
& \leq\left(1-t\left(1-\sqrt{\frac{1-\alpha}{\lambda}}\right)\right)\left\|x_{t}-p\right\|+t\|F(p)\| \\
& =(1-t \bar{\gamma})\left\|x_{t}-p\right\|+t\|F(p)\|,
\end{aligned}
$$

where $\bar{\gamma}=1-\sqrt{\frac{1-\alpha}{\lambda}}$. Thus, it immediately follows that

$$
\left\|x_{t}-p\right\| \leq \frac{1}{\bar{\gamma}}\|F(p)\|
$$

Therefore, $\left\{x_{t}\right\}$ is bounded and so are the nets $\left\{G\left(x_{t}\right)\right\},\left\{F\left(G\left(x_{t}\right)\right)\right\}$. Furthermore, by Lemma 2.10 , we know that $G: C \rightarrow C$ is nonexpansive. Thus,

$$
\left\|x_{t}-G\left(x_{t}\right)\right\|=\left\|\Pi_{C}(I-t F) G\left(x_{t}\right)-\Pi_{C} G\left(x_{t}\right)\right\| \leq t\left\|F\left(G\left(x_{t}\right)\right)\right\| \rightarrow 0
$$


as $t \rightarrow 0$. That is,

$$
\lim _{t \rightarrow 0}\left\|x_{t}-G\left(x_{t}\right)\right\|=0
$$

Furthermore, we show that $\left\{x_{t}\right\}$ is relatively norm-compact as $t \rightarrow 0^{+}$. Assume that $\left\{t_{n}\right\} \subset$ $(0,1)$ is such that $t_{n} \rightarrow 0^{+}$as $n \rightarrow \infty$. Put $x_{n}:=x_{t_{n}}$. Then it is clear that

$$
\left\|x_{n}-G\left(x_{n}\right)\right\| \rightarrow 0 \quad \text { as } n \rightarrow \infty .
$$

We can rewrite (3.20) as

$$
x_{t}=\Pi_{C}(I-t F) G\left(x_{t}\right)-(I-t F) G\left(x_{t}\right)+(I-t F) G\left(x_{t}\right) .
$$

For any $p \in \Omega \subset C$, by Lemma 2.5 , we have

$$
\begin{aligned}
\left\langle x_{t}\right. & \left.-(I-t F) G\left(x_{t}\right), J\left(x_{t}-p\right)\right\rangle \\
& =\left\langle\Pi_{C}(I-t F) G\left(x_{t}\right)-(I-t F) G\left(x_{t}\right), J\left(\Pi_{C}(I-t F) G\left(x_{t}\right)-p\right)\right\rangle \leq 0 .
\end{aligned}
$$

According to this fact, we deduce that

$$
\begin{aligned}
\left\|x_{t}-p\right\|^{2} & =\left\langle x_{t}-p, J\left(x_{t}-p\right)\right\rangle \\
& =\left\langle x_{t}-(I-t F) G\left(x_{t}\right), J\left(x_{t}-p\right)\right\rangle+\left\langle(I-t F) G\left(x_{t}\right)-p, J\left(x_{t}-p\right)\right\rangle \\
& \leq\left\langle(I-t F) G\left(x_{t}\right)-p, J\left(x_{t}-p\right)\right\rangle \\
& =\left\langle(I-t F)\left(G\left(x_{t}\right)-p\right), J\left(x_{t}-p\right)\right\rangle-t\left\langle F(p), J\left(x_{t}-p\right)\right\rangle \\
& \leq(1-t \bar{\gamma})\left\|G\left(x_{t}\right)-p\right\|\left\|x_{t}-p\right\|-t\left\langle F(p), J\left(x_{t}-p\right)\right\rangle \\
& \leq(1-t \bar{\gamma})\left\|x_{t}-p\right\|^{2}-t\left\langle F(p), J\left(x_{t}-p\right)\right\rangle .
\end{aligned}
$$

It turns out that

$$
\left\|x_{t}-p\right\|^{2} \leq \frac{1}{\bar{\gamma}}\left\langle F(p), J\left(p-x_{t}\right)\right\rangle, \quad \forall p \in \Omega .
$$

In particular,

$$
\left\|x_{n}-p\right\|^{2} \leq \frac{1}{\bar{\gamma}}\left\langle F(p), J\left(p-x_{n}\right)\right\rangle, \quad \forall p \in \Omega .
$$

Since $\left\{x_{n}\right\}$ is bounded, we may assume, without loss of generality, that $\left\{x_{n}\right\}$ converges weakly to a point $\tilde{x} \in C$. Noticing (3.23), we can use Lemma 2.6 to get $\tilde{x} \in \Omega$. Therefore, we can substitute $\tilde{x}$ for $p$ in (3.25) to get

$$
\left\|x_{n}-\tilde{x}\right\|^{2} \leq \frac{1}{\bar{\gamma}}\left\langle F(\tilde{x}), J\left(\tilde{x}-x_{n}\right)\right\rangle
$$

which together with the weakly sequential continuity of $J$ implies that

$$
\lim _{n \rightarrow \infty}\left\|x_{n}-\tilde{x}\right\|=0
$$

This has proven the relative norm compactness of the net $\left\{x_{n}\right\}$ as $t \rightarrow 0^{+}$. 
We also show that $\tilde{x}$ solves the VIP (3.21). From (3.20), we have

$$
\begin{aligned}
x_{t}= & \Pi_{C}(I-t F) G\left(x_{t}\right)-(I-t F) G\left(x_{t}\right)+(I-t F) G\left(x_{t}\right) \\
\Rightarrow \quad x_{t}= & \Pi_{C}(I-t F) G\left(x_{t}\right)-(I-t F) G\left(x_{t}\right) \\
& \quad-\left((I-t F) x_{t}-(I-t F) G\left(x_{t}\right)\right)+x_{t}-t F\left(x_{t}\right) \\
& \Rightarrow \quad F\left(x_{t}\right)=\frac{1}{t}\left[\Pi_{C}(I-t F) G\left(x_{t}\right)-(I-t F) G\left(x_{t}\right)-\left((I-t F) x_{t}-(I-t F) G\left(x_{t}\right)\right)\right] .
\end{aligned}
$$

For any $z \in \Omega$, utilizing the nonexpansivity of $G$, we obtain that

$$
\left\langle x_{t}-G\left(x_{t}\right), J\left(x_{t}-z\right)\right\rangle=\left\langle(I-G) x_{t}-(I-G) z, J\left(x_{t}-z\right)\right\rangle \geq 0,
$$

and hence,

$$
\begin{aligned}
\left\langle F\left(x_{t}\right), J\left(x_{t}-z\right)\right\rangle= & \frac{1}{t}\left\langle\Pi_{C}(I-t F) G\left(x_{t}\right)-(I-t F) G\left(x_{t}\right), J\left(x_{t}-z\right)\right\rangle \\
& -\frac{1}{t}\left\langle\left((I-t F) x_{t}-(I-t F) G\left(x_{t}\right)\right), J\left(x_{t}-z\right)\right\rangle \\
\leq & -\frac{1}{t}\left\langle\left((I-t F) x_{t}-(I-t F) G\left(x_{t}\right)\right), J\left(x_{t}-z\right)\right\rangle \\
= & -\frac{1}{t}\left\langle x_{t}-G\left(x_{t}\right), J\left(x_{t}-z\right)\right\rangle+\left\langle F\left(x_{t}\right)-F\left(G\left(x_{t}\right)\right), J\left(x_{t}-z\right)\right\rangle \\
\leq & \left\langle F\left(x_{t}\right)-F\left(G\left(x_{t}\right)\right), J\left(x_{t}-z\right)\right\rangle .
\end{aligned}
$$

Therefore,

$$
\left\langle F\left(x_{t}\right), J\left(x_{t}-z\right)\right\rangle \leq\left\langle F\left(x_{t}\right)-F\left(G\left(x_{t}\right)\right), J\left(x_{t}-z\right)\right\rangle .
$$

Since $F$ is $\alpha$-strongly accretive, we have

$$
0 \leq \alpha\left\|x_{t}-z\right\|^{2} \leq\left\langle F\left(x_{t}\right)-F(z), J\left(x_{t}-z\right)\right\rangle
$$

It follows that

$$
\left\langle F(z), J\left(x_{t}-z\right)\right\rangle \leq\left\langle F\left(x_{t}\right), J\left(x_{t}-z\right)\right\rangle \text {. }
$$

Combining (3.27) and (3.28), we get

$$
\left\langle F(z), J\left(x_{t}-z\right)\right\rangle \leq\left\langle F\left(x_{t}\right)-F\left(G\left(x_{t}\right)\right), J\left(x_{t}-z\right)\right\rangle .
$$

Now, replacing $t$ in (3.29) with $t_{n}$ and letting $n \rightarrow \infty$, noticing that $x_{t_{n}} \rightarrow \tilde{x}$ and $x_{t_{n}}-$ $G\left(x_{t_{n}}\right) \rightarrow 0$ as $n \rightarrow \infty$, we derive

$$
\langle F(z), J(\tilde{x}-z)\rangle \leq 0, \quad \forall z \in \Omega,
$$

which is equivalent to its dual variational inequality (see Lemma 2.8)

$$
\langle F(\tilde{x}), J(\tilde{x}-z)\rangle \leq 0, \quad \forall z \in \Omega .
$$


That is, $\tilde{x} \in \Omega$ is a solution of VIP (3.21). Now, we show that the solution set of VIP (3.21) is a singleton. As a matter of fact, we assume that $\bar{x} \in \Omega$ is another solution of VIP (3.21). Then, we have

$$
\langle F(\bar{x}), J(\bar{x}-\tilde{x})\rangle \leq 0
$$

From (3.30), we have

$$
\langle F(\tilde{x}), J(\tilde{x}-\bar{x})\rangle \leq 0
$$

So,

$$
\begin{aligned}
& \langle F(\bar{x}), J(\bar{x}-\tilde{x})\rangle+\langle F(\tilde{x}), J(\tilde{x}-\bar{x})\rangle \leq 0 \\
& \Rightarrow \quad\langle F(\bar{x})-F(\tilde{x}), J(\bar{x}-\tilde{x})\rangle \leq 0 \\
& \Rightarrow \quad \alpha\|\bar{x}-\tilde{x}\|^{2} \leq 0 .
\end{aligned}
$$

Therefore, $\bar{x}=\tilde{x}$. In summary, we have shown that each (strong) cluster point of the net $\left\{x_{t}\right\}$ (as $t \rightarrow 0$ ) equals to $\tilde{x}$. Therefore, $x_{t} \rightarrow \tilde{x}$ as $t \rightarrow 0$. This completes the proof.

\section{Explicit iterative schemes}

In this section, we propose explicit iterative schemes which are the discretization of the implicit iterative schemes, and show the strong convergence theorems.

Algorithm 4.1 Let $C$ be a nonempty closed convex subset of a real smooth Banach space $X$. Let $\Pi_{C}$ be a sunny nonexpansive retraction from $X$ onto $C$. Let $B_{1}, B_{2}: C \rightarrow X$ be two nonlinear mappings. Let $f \in \Xi_{C}$ and $F: C \rightarrow X$ be $\alpha$-strongly accretive and $\lambda$-strictly pseudocontractive. For arbitrarily given $x_{0} \in C$, let the sequence $\left\{x_{n}\right\}$ be generated iteratively by

$$
x_{n+1}=\beta_{n} f\left(x_{n}\right)+\left(1-\beta_{n}\right) \Pi_{C}\left(I-\gamma_{n} F\right) \Pi_{C}\left(I-\mu_{1} B_{1}\right) \Pi_{C}\left(I-\mu_{2} B_{2}\right) x_{n}, \quad \forall n \geq 0,
$$

where $\left\{\beta_{n}\right\} \subset(0,1),\left\{\gamma_{n}\right\} \subset[0,1)$ and $\mu_{1}, \mu_{2}$ are two positive numbers.

In particular, if $B_{1}=B_{2}=A$, then (4.1) reduces to the following:

$$
x_{n+1}=\beta_{n} f\left(x_{n}\right)+\left(1-\beta_{n}\right) \Pi_{C}\left(I-\gamma_{n} F\right) \Pi_{C}\left(I-\mu_{1} A\right) \Pi_{C}\left(I-\mu_{2} A\right) x_{n}, \quad \forall n \geq 0 .
$$

Theorem 4.1 Let $C$ be a nonempty closed convex subset of a real 2-uniformly smooth Banach space $X$. Let $\Pi_{C}$ be a sunny nonexpansive retraction from $X$ onto $C$. Let the mapping $B_{i}: C \rightarrow X$ be $\alpha_{i}$-inverse-strongly accretive for $i=1,2$. Let $f \in \Xi_{C}$ with coefficient $\rho \in(0,1)$, and let $F: C \rightarrow X$ be $\alpha$-strongly accretive and $\lambda$-strictly pseudocontractive with $\alpha+\lambda \geq 1$. Assume that $0<\mu_{i} \leq \frac{\alpha_{i}}{\kappa^{2}}$ for $i=1,2$. Let $\Omega \neq \emptyset$, and assume that

(i) $\beta_{n} \rightarrow 0$ and $\sum_{n=0}^{\infty} \beta_{n}=\infty$;

(ii) $\lim _{n \rightarrow \infty} \gamma_{n} / \beta_{n}=0$;

(iii) $\sum_{n=1}^{\infty}\left|\beta_{n}-\beta_{n-1}\right|<\infty$ or $\lim _{n \rightarrow \infty} \beta_{n-1} / \beta_{n}=1$;

(iv) $\sum_{n=1}^{\infty}\left|\gamma_{n}-\gamma_{n-1}\right|<\infty$ or $\lim _{n \rightarrow \infty}\left|\gamma_{n}-\gamma_{n-1}\right| / \beta_{n}=0$. 
Then the sequence $\left\{x_{n}\right\}$ generated by scheme (4.1) converges strongly to $Q(f)$, where $Q$ : $\Xi_{C} \rightarrow \Omega$ is defined by (3.15).

Proof For each $n \geq 0$, let $S_{n}$ be defined by

$$
S_{n} x=\Pi_{C}\left(I-\gamma_{n} F\right) \Pi_{C}\left(I-\mu_{1} B_{1}\right) \Pi_{C}\left(I-\mu_{2} B_{2}\right) x, \quad \forall x \in C .
$$

Then we know that

(i) the scheme (4.1) is rewritten as

$$
x_{n+1}=\beta_{n} f\left(x_{n}\right)+\left(1-\beta_{n}\right) S_{n} x_{n}, \quad \forall n \geq 0 ;
$$

(ii) $S_{n}$ is nonexpansive by the similar argument to that of the nonexpansivity of $S_{t}$ in (3.5);

(iii) $S_{n} p=\Pi_{C}\left(I-\gamma_{n} F\right) p$ for all $p \in \Omega$.

Thus, we deduce that for $p \in \Omega$,

$$
\begin{aligned}
& \left\|x_{n+1}-p\right\| \\
& \quad=\left\|\beta_{n}\left(f\left(x_{n}\right)-p\right)+\left(1-\beta_{n}\right)\left(S_{n} x_{n}-p\right)\right\| \\
& \quad \leq \beta_{n}\left\|f\left(x_{n}\right)-p\right\|+\left(1-\beta_{n}\right)\left\|S_{n} x_{n}-p\right\| \\
& \quad \leq \beta_{n}\left(\left\|f\left(x_{n}\right)-f(p)\right\|+\|f(p)-p\|\right)+\left(1-\beta_{n}\right)\left(\left\|S_{n} x_{n}-S_{n} p\right\|+\left\|S_{n} p-p\right\|\right) \\
& \quad \leq \beta_{n} \rho\left\|x_{n}-p\right\|+\beta_{n}\|f(p)-p\|+\left(1-\beta_{n}\right)\left(\left\|x_{n}-p\right\|+\left\|\Pi_{C}\left(I-\gamma_{n} F\right) p-\Pi_{C} p\right\|\right) \\
& \quad \leq\left(1-\beta_{n}(1-\rho)\right)\left\|x_{n}-p\right\|+\beta_{n}\|f(p)-p\|+\gamma_{n}\|F(p)\| .
\end{aligned}
$$

Because $\lim _{n \rightarrow \infty} \gamma_{n} / \beta_{n}=0$, we may assume without loss of generality that $\gamma_{n} \leq \beta_{n}$ for all $n \geq 0$. Hence, from (4.4), we get

$$
\left\|x_{n+1}-p\right\| \leq \beta_{n}(\|f(p)-p\|+\|F(p)\|)+\left(1-\beta_{n}(1-\rho)\right)\left\|x_{n}-p\right\|, \quad \forall n \geq 0 .
$$

By induction, we conclude that

$$
\left\|x_{n}-p\right\| \leq \max \left\{\frac{\|f(p)-p\|+\|F(p)\|}{1-\rho},\left\|x_{0}-p\right\|\right\}, \quad \forall n \geq 0 .
$$

Therefore, $\left\{x_{n}\right\}$ is bounded, so are the sequences $\left\{f\left(x_{n}\right)\right\},\left\{G\left(x_{n}\right)\right\},\left\{S_{n} x_{n}\right\}$ and $\left\{F\left(G\left(x_{n}\right)\right)\right\}$. Also, from (4.1), we have

$$
\begin{aligned}
\left\|x_{n+1}-G\left(x_{n}\right)\right\| & \leq \beta_{n}\left\|f\left(x_{n}\right)-G\left(x_{n}\right)\right\|+\left(1-\beta_{n}\right)\left\|S_{n} x_{n}-G\left(x_{n}\right)\right\| \\
& =\beta_{n}\left\|f\left(x_{n}\right)-G\left(x_{n}\right)\right\|+\left(1-\beta_{n}\right)\left\|\Pi_{C}\left(I-\gamma_{n} F\right) G\left(x_{n}\right)-\Pi_{C} G\left(x_{n}\right)\right\| \\
& \leq \beta_{n}\left\|f\left(x_{n}\right)-G\left(x_{n}\right)\right\|+\left(1-\beta_{n}\right) \gamma_{n}\left\|F\left(G\left(x_{n}\right)\right)\right\| \\
& \leq \beta_{n}\left\|f\left(x_{n}\right)-G\left(x_{n}\right)\right\|+\gamma_{n}\left\|F\left(G\left(x_{n}\right)\right)\right\|,
\end{aligned}
$$

which together with $\beta_{n} \rightarrow 0$ and $\gamma_{n} \rightarrow 0$, implies that

$$
\lim _{n \rightarrow \infty}\left\|x_{n+1}-G\left(x_{n}\right)\right\|=0 .
$$


Now, we note that

$$
\begin{aligned}
x_{n+1}-x_{n}= & \beta_{n} f\left(x_{n}\right)+\left(1-\beta_{n}\right) S_{n} x_{n}-\beta_{n-1} f\left(x_{n}\right)-\left(1-\beta_{n-1}\right) S_{n-1} x_{n-1} \\
= & \left(\beta_{n}-\beta_{n-1}\right)\left(f\left(x_{n-1}\right)-S_{n-1} x_{n-1}\right)+\beta_{n}\left(f\left(x_{n}\right)-f\left(x_{n-1}\right)\right) \\
& +\left(1-\beta_{n}\right)\left(S_{n} x_{n}-S_{n} x_{n-1}\right)+\left(1-\beta_{n}\right)\left(S_{n} x_{n-1}-S_{n-1} x_{n-1}\right) .
\end{aligned}
$$

Thus, it follows that

$$
\begin{aligned}
\| x_{n+1} & -x_{n} \| \\
\leq & \left|\beta_{n}-\beta_{n-1}\right|\left\|f\left(x_{n-1}\right)-S_{n-1} x_{n-1}\right\|+\beta_{n}\left\|f\left(x_{n}\right)-f\left(x_{n-1}\right)\right\|+\left(1-\beta_{n}\right)\left\|S_{n} x_{n}-S_{n} x_{n-1}\right\| \\
& +\left(1-\beta_{n}\right)\left\|S_{n} x_{n-1}-S_{n-1} x_{n-1}\right\| \\
\leq & \left|\beta_{n}-\beta_{n-1}\right|\left\|f\left(x_{n-1}\right)-S_{n-1} x_{n-1}\right\|+\beta_{n} \rho\left\|x_{n}-x_{n-1}\right\|+\left(1-\beta_{n}\right)\left\|x_{n}-x_{n-1}\right\| \\
& +\left\|\Pi_{C}\left(I-\gamma_{n} F\right) G\left(x_{n-1}\right)-\Pi_{C}\left(I-\gamma_{n-1} F\right) G\left(x_{n-1}\right)\right\| \\
\leq & M\left|\beta_{n}-\beta_{n-1}\right|+\beta_{n} \rho\left\|x_{n}-x_{n-1}\right\|+\left(1-\beta_{n}\right)\left\|x_{n}-x_{n-1}\right\| \\
& +\left|\gamma_{n}-\gamma_{n-1}\right|\left\|F\left(G\left(x_{n-1}\right)\right)\right\| \\
= & \left(1-\beta_{n}(1-\rho)\right)\left\|x_{n}-x_{n-1}\right\|+M\left(\left|\beta_{n}-\beta_{n-1}\right|+\left|\gamma_{n}-\gamma_{n-1}\right|\right),
\end{aligned}
$$

where $\sup _{n \geq 0}\left\{\left\|f\left(x_{n}\right)-S_{n} x_{n}\right\|+\left\|F\left(G\left(x_{n}\right)\right)\right\|\right\} \leq M$ for some $M>0$. So, utilizing Lemma 2.1, we obtain that

$$
\lim _{n \rightarrow \infty}\left\|x_{n+1}-x_{n}\right\|=0
$$

This together with (4.6) implies that

$$
\lim _{n \rightarrow \infty}\left\|x_{n}-G\left(x_{n}\right)\right\|=0 .
$$

Let us show that

$$
\limsup _{n \rightarrow \infty}\left\langle\tilde{x}-f(\tilde{x}), J\left(\tilde{x}-x_{n}\right)\right\rangle \leq 0
$$

where $\tilde{x}=Q(f)$. Indeed we can write

$$
x_{t}-x_{n}=t\left(f\left(x_{t}\right)-x_{n}\right)+(1-t)\left(S_{t} x_{t}-x_{n}\right) .
$$

Putting

$$
a_{n}(t)=\left(\left\|G\left(x_{n}\right)-x_{n}\right\|+\theta_{t}\left\|F\left(G\left(x_{n}\right)\right)\right\|\right)\left[2\left\|x_{t}-x_{n}\right\|+\left\|G\left(x_{n}\right)-x_{n}\right\|+\theta_{t}\left\|F\left(G\left(x_{n}\right)\right)\right\|\right] \text {, }
$$

and using Lemma 2.2, we obtain

$$
\begin{aligned}
\left\|x_{t}-x_{n}\right\|^{2} & \leq(1-t)^{2}\left\|S_{t} x_{t}-x_{n}\right\|^{2}+2 t\left\langle f\left(x_{t}\right)-x_{n}, J\left(x_{t}-x_{n}\right)\right\rangle \\
& \leq(1-t)^{2}\left(\left\|S_{t} x_{t}-S_{t} x_{n}\right\|+\left\|S_{t} x_{n}-x_{n}\right\|\right)^{2}
\end{aligned}
$$




$$
\begin{aligned}
& +2 t\left\langle f\left(x_{t}\right)-x_{t}, J\left(x_{t}-x_{n}\right)\right\rangle+2 t\left\|x_{t}-x_{n}\right\|^{2} \\
\leq & (1-t)^{2}\left(\left\|x_{t}-x_{n}\right\|+\left\|\Pi_{C}\left(I-\theta_{t} F\right) G\left(x_{n}\right)-\Pi_{C} x_{n}\right\|\right)^{2} \\
& +2 t\left\langle f\left(x_{t}\right)-x_{t}, J\left(x_{t}-x_{n}\right)\right\rangle+2 t\left\|x_{t}-x_{n}\right\|^{2} \\
\leq & (1-t)^{2}\left(\left\|x_{t}-x_{n}\right\|+\left\|G\left(x_{n}\right)-x_{n}\right\|+\theta_{t}\left\|F\left(G\left(x_{n}\right)\right)\right\|\right)^{2} \\
& +2 t\left\langle f\left(x_{t}\right)-x_{t}, J\left(x_{t}-x_{n}\right)\right\rangle+2 t\left\|x_{t}-x_{n}\right\|^{2} \\
\leq & (1-t)^{2}\left\|x_{t}-x_{n}\right\|^{2}+a_{n}(t) \\
& +2 t\left\langle f\left(x_{t}\right)-x_{t}, J\left(x_{t}-x_{n}\right)\right\rangle+2 t\left\|x_{t}-x_{n}\right\|^{2} .
\end{aligned}
$$

The last inequality implies that

$$
\left\langle x_{t}-f\left(x_{t}\right), J\left(x_{t}-x_{n}\right)\right\rangle \leq \frac{t}{2}\left\|x_{t}-x_{n}\right\|^{2}+\frac{1}{2 t} a_{n}(t)
$$

Note that

$$
\begin{aligned}
\limsup _{n \rightarrow \infty} \frac{1}{2 t} a_{n}(t)= & \limsup _{n \rightarrow \infty} \frac{1}{2 t}\left(\left\|G\left(x_{n}\right)-x_{n}\right\|+\theta_{t}\left\|F\left(G\left(x_{n}\right)\right)\right\|\right) \\
& \times\left[2\left\|x_{t}-x_{n}\right\|+\left\|G\left(x_{n}\right)-x_{n}\right\|+\theta_{t}\left\|F\left(G\left(x_{n}\right)\right)\right\|\right] \\
& =\frac{\theta_{t}}{2 t} \limsup _{n \rightarrow \infty}\left\|F\left(G\left(x_{n}\right)\right)\right\|\left[2\left\|x_{t}-x_{n}\right\|+\theta_{t}\left\|F\left(G\left(x_{n}\right)\right)\right\|\right] \\
\leq & \frac{\theta_{t}}{2 t} \limsup _{n \rightarrow \infty}\left\|F\left(G\left(x_{n}\right)\right)\right\|\left[2\left\|x_{t}-x_{n}\right\|+2\left\|F\left(G\left(x_{n}\right)\right)\right\|\right] \\
\leq & \frac{\theta_{t}}{t} M_{0}^{2},
\end{aligned}
$$

where $M_{0}>0$ is a constant such that $M_{0} \geq\left\|F\left(G\left(x_{n}\right)\right)\right\|+\left\|x_{t}-x_{n}\right\|$ for all $n \geq 1$ and $t \in(0,1)$. It follows from (4.9) that

$$
\limsup _{n \rightarrow \infty}\left\langle x_{t}-f\left(x_{t}\right), J\left(x_{t}-x_{n}\right)\right\rangle \leq \frac{t}{2} M_{0}^{2}+\frac{\theta_{t}}{t} M_{0}^{2}
$$

Taking the limsup as $t \rightarrow 0$ in (4.10), and noticing the fact that the two limits are interchangeable due to the fact that the duality map $J$ is norm-to-norm uniformly continuous on bounded sets of $X$, we obtain (4.8).

Finally, we show that $x_{n} \rightarrow \tilde{x}$. Write

$$
x_{n+1}-\tilde{x}=\beta_{n}\left(f\left(x_{n}\right)-\tilde{x}\right)+\left(1-\beta_{n}\right)\left(S_{n} x_{n}-\tilde{x}\right),
$$

and apply Lemma 2.2 to get

$$
\begin{aligned}
\left\|x_{n+1}-\tilde{x}\right\|^{2} & \leq\left(1-\beta_{n}\right)^{2}\left\|S_{n} x_{n}-\tilde{x}\right\|^{2}+2 \beta_{n}\left\langle f\left(x_{n}\right)-\tilde{x}, J\left(x_{n+1}-\tilde{x}\right)\right\rangle \\
& \leq\left(1-\beta_{n}\right)^{2}\left(\left\|S_{n} x_{n}-S_{n} \tilde{x}\right\|+\left\|S_{n} \tilde{x}-\tilde{x}\right\|\right)^{2}+2 \beta_{n}\left\{f\left(x_{n}\right)-\tilde{x}, J\left(x_{n+1}-\tilde{x}\right)\right\rangle \\
& \leq\left(1-\beta_{n}\right)^{2}\left(\left\|x_{n}-\tilde{x}\right\|+\left\|\Pi_{C}\left(I-\gamma_{n} F\right) \tilde{x}-\tilde{x}\right\|\right)^{2}+2 \beta_{n}\left\langle f\left(x_{n}\right)-\tilde{x}, J\left(x_{n+1}-\tilde{x}\right)\right\rangle \\
& \leq\left(1-\beta_{n}\right)^{2}\left(\left\|x_{n}-\tilde{x}\right\|+\gamma_{n}\|F(\tilde{x})\|\right)^{2}+2 \beta_{n}\left\langle f\left(x_{n}\right)-f(\tilde{x}), J\left(x_{n+1}-\tilde{x}\right)\right\rangle
\end{aligned}
$$




$$
\begin{aligned}
& +2 \beta_{n}\left\langle f(\tilde{x})-\tilde{x}, J\left(x_{n+1}-\tilde{x}\right)\right\rangle \\
\leq & \left(1-\beta_{n}\right)^{2}\left\|x_{n}-\tilde{x}\right\|^{2}+\gamma_{n}\|F(\tilde{x})\|\left(2\left\|x_{n}-\tilde{x}\right\|+\gamma_{n}\|F(\tilde{x})\|\right) \\
& +2 \beta_{n} \rho\left\|x_{n}-\tilde{x}\right\|\left\|x_{n+1}-\tilde{x}\right\|+2 \beta_{n}\left\langle f(\tilde{x})-\tilde{x}, J\left(x_{n+1}-\tilde{x}\right)\right\rangle \\
\leq & \left(1-\beta_{n}\right)^{2}\left\|x_{n}-\tilde{x}\right\|^{2}+\gamma_{n}\|F(\tilde{x})\|\left(2\left\|x_{n}-\tilde{x}\right\|+\|F(\tilde{x})\|\right) \\
& +\rho \beta_{n}\left(\left\|x_{n}-\tilde{x}\right\|^{2}+\left\|x_{n+1}-\tilde{x}\right\|^{2}\right)+2 \beta_{n}\left\langle f(\tilde{x})-\tilde{x}, J\left(x_{n+1}-\tilde{x}\right)\right\rangle .
\end{aligned}
$$

It then follows that

$$
\begin{aligned}
\left\|x_{n+1}-\tilde{x}\right\|^{2} \leq & \frac{1-(2-\rho) \beta_{n}+\beta_{n}^{2}}{1-\rho \beta_{n}}\left\|x_{n}-\tilde{x}\right\|^{2} \\
& +\frac{\beta_{n}}{1-\rho \beta_{n}}\left[\frac{\gamma_{n}}{\beta_{n}}\|F(\tilde{x})\|\left(2\left\|x_{n}-\tilde{x}\right\|+\|F(\tilde{x})\|\right)+2\left\langle f(\tilde{x})-\tilde{x}, J\left(x_{n+1}-\tilde{x}\right)\right\rangle\right] \\
= & \left(1-\frac{2(1-\rho) \beta_{n}}{1-\rho \beta_{n}}\right)\left\|x_{n}-\tilde{x}\right\|^{2} \\
& +\frac{2(1-\rho) \beta_{n}}{1-\rho \beta_{n}} \cdot \frac{1}{2(1-\rho)}\left[\frac{\gamma_{n}}{\beta_{n}}\|F(\tilde{x})\|\left(2\left\|x_{n}-\tilde{x}\right\|+\|F(\tilde{x})\|\right)\right. \\
& \left.+\beta_{n}\left\|x_{n}-\tilde{x}\right\|^{2}+2\left\langle f(\tilde{x})-\tilde{x}, J\left(x_{n+1}-\tilde{x}\right)\right\rangle\right] .
\end{aligned}
$$

Put

$$
\tilde{\alpha}_{n}=\frac{2(1-\rho) \beta_{n}}{1-\rho \beta_{n}}
$$

and

$$
\tilde{\beta}_{n}=\frac{1}{2(1-\rho)}\left[\frac{\gamma_{n}}{\beta_{n}}\|F(\tilde{x})\|\left(2\left\|x_{n}-\tilde{x}\right\|+\|F(\tilde{x})\|\right)+\beta_{n}\left\|x_{n}-\tilde{x}\right\|^{2}+2\left\langle f(\tilde{x})-\tilde{x}, J\left(x_{n+1}-\tilde{x}\right)\right\rangle\right] .
$$

It follows that

$$
\left\|x_{n+1}-\tilde{x}\right\|^{2} \leq\left(1-\tilde{\alpha}_{n}\right)\left\|x_{n}-\tilde{x}\right\|^{2}+\tilde{\alpha}_{n} \tilde{\beta}_{n} .
$$

Observe that

$$
\begin{aligned}
& \limsup _{n \rightarrow \infty}\left\langle f(\tilde{x})-\tilde{x}, J\left(x_{n+1}-\tilde{x}\right)\right\rangle \\
& \quad=\limsup _{n \rightarrow \infty}\left(\left\langle f(\tilde{x})-\tilde{x}, J\left(x_{n}-\tilde{x}\right)\right\rangle+\left\langle f(\tilde{x})-\tilde{x}, J\left(x_{n+1}-\tilde{x}\right)-J\left(x_{n}-\tilde{x}\right)\right\rangle\right) \\
& \quad=\limsup _{n \rightarrow \infty}\left\langle f(\tilde{x})-\tilde{x}, J\left(x_{n}-\tilde{x}\right)\right\rangle \leq 0
\end{aligned}
$$

due to (4.8). It is easily seen from conditions (i), (ii) that

$$
\tilde{\alpha}_{n} \rightarrow 0, \quad \sum_{n=0}^{\infty} \tilde{\alpha}_{n}=\infty \quad \text { and } \quad \limsup _{n \rightarrow \infty} \tilde{\beta}_{n} \leq 0 .
$$

Finally, apply Lemma 2.2 to (4.11) to conclude that $x_{n} \rightarrow \tilde{x}$. 
Algorithm 4.2 Let $C$ be a nonempty closed convex subset of a real smooth Banach space $X$. Let $\Pi_{C}$ be a sunny nonexpansive retraction from $X$ onto $C$. Let $B_{1}, B_{2}: C \rightarrow X$ be two nonlinear mappings. Let $F: C \rightarrow X$ be $\alpha$-strongly accretive and $\lambda$-strictly pseudocontractive. For arbitrarily given $x_{0} \in C$, let the sequence $\left\{x_{n}\right\}$ be generated iteratively by

$$
x_{n+1}=\beta_{n} x_{n}+\left(1-\beta_{n}\right) \Pi_{C}\left(I-\alpha_{n} F\right) \Pi_{C}\left(I-\mu_{1} B_{1}\right) \Pi_{C}\left(I-\mu_{2} B_{2}\right) x_{n}, \quad \forall n \geq 0,
$$

where $\left\{\alpha_{n}\right\}$ and $\left\{\beta_{n}\right\}$ are two sequences in $[0,1]$ and $\mu_{1}, \mu_{2}$ are two positive numbers.

In particular, if $B_{1}=B_{2}=A$, then (4.12) reduces to the following:

$$
x_{n+1}=\beta_{n} x_{n}+\left(1-\beta_{n}\right) \Pi_{C}\left(I-\alpha_{n} F\right) \Pi_{C}\left(I-\mu_{1} A\right) \Pi_{C}\left(I-\mu_{2} A\right) x_{n}, \quad \forall n \geq 0 .
$$

Theorem 4.2 Let $C$ be a nonempty closed convex subset of a 2-uniformly smooth Banach space $X$ with weakly sequentially continuous duality mapping J. Let $\Pi_{C}$ be a sunny nonexpansive retraction from $X$ onto $C$. Let the mapping $B_{i}: C \rightarrow X$ be $\alpha_{i}$-inverse-strongly accretive with $0<\mu_{i} \leq \frac{\alpha_{i}}{\kappa^{2}}$ for $i=1,2$. Let $F: C \rightarrow X$ be $\alpha$-strongly accretive and $\lambda$-strictly pseudocontractive with $\alpha+\lambda>1$. Let $\Omega \neq \emptyset$, and let $\left\{x_{n}\right\}$ be the sequence generated by (4.12). Assume that the sequences $\left\{\alpha_{n}\right\}$ and $\left\{\beta_{n}\right\}$ satisfy the following conditions:

(i) $\lim _{n \rightarrow \infty} \alpha_{n}=0$ and $\sum_{n=0}^{\infty} \alpha_{n}=\infty$;

(ii) $0<\liminf _{n \rightarrow \infty} \beta_{n} \leq \lim \sup _{n \rightarrow \infty} \beta_{n}<1$.

Then the sequence $\left\{x_{n}\right\}$ converges strongly to the unique solution $\tilde{x} \in \Omega$ of VIP (3.21).

Proof Take a fixed $p \in \Omega$ arbitrarily. Then $G(p)=p$ due to Lemma 1.1. By Lemma 2.10, we have

$$
\left\|G\left(x_{n}\right)-p\right\|=\left\|G\left(x_{n}\right)-G(p)\right\| \leq\left\|x_{n}-p\right\|, \quad \forall n \geq 0 .
$$

Hence, it follows from Proposition 3.1(ii) that

$$
\begin{aligned}
& \left\|x_{n+1}-p\right\| \\
& \quad=\left\|\beta_{n}\left(x_{n}-p\right)+\left(1-\beta_{n}\right)\left(\Pi_{C}\left(I-\alpha_{n} F\right) G\left(x_{n}\right)-p\right)\right\| \\
& \quad \leq \beta_{n}\left\|x_{n}-p\right\|+\left(1-\beta_{n}\right)\left\|\left(I-\alpha_{n} F\right) G\left(x_{n}\right)-p\right\| \\
& \quad=\beta_{n}\left\|x_{n}-p\right\|+\left(1-\beta_{n}\right)\left\|\left(I-\alpha_{n} F\right) G\left(x_{n}\right)-\left(I-\alpha_{n} F\right) G(p)+\left(I-\alpha_{n} F\right) G(p)-p\right\| \\
& \quad \leq \beta_{n}\left\|x_{n}-p\right\|+\left(1-\beta_{n}\right)\left[\left\|\left(I-\alpha_{n} F\right) G\left(x_{n}\right)-\left(I-\alpha_{n} F\right) G(p)\right\|+\left\|\left(I-\alpha_{n} F\right) p-p\right\|\right] \\
& \quad \leq \beta_{n}\left\|x_{n}-p\right\|+\left(1-\beta_{n}\right)\left[\left(1-\alpha_{n} \bar{\gamma}\right)\left\|x_{n}-p\right\|+\alpha_{n}\|F(p)\|\right] \\
& \quad=\left(1-\left(1-\beta_{n}\right) \alpha_{n} \bar{\gamma}\right)\left\|x_{n}-p\right\|+\left(1-\beta_{n}\right) \alpha_{n} \bar{\gamma} \frac{\|F(p)\|}{\bar{\gamma}},
\end{aligned}
$$

where $\bar{\gamma}=1-\sqrt{\frac{1-\alpha}{\lambda}}$. By induction, we deduce that

$$
\left\|x_{n+1}-p\right\| \leq \max \left\{\left\|x_{0}-p\right\|, \frac{\|F(p)\|}{\bar{\gamma}}\right\} .
$$

Therefore, $\left\{x_{n}\right\}$ is bounded. Hence, $\left\{G\left(x_{n}\right)\right\}$ and $\left\{F\left(G\left(x_{n}\right)\right)\right\}$ are also bounded. Now, set $v_{n}=\Pi_{C}\left(I-\alpha_{n} F\right) G\left(x_{n}\right)$ for all $n \geq 0$. Then $x_{n+1}=\beta_{n} x_{n}+\left(1-\beta_{n}\right) v_{n}$ for $n \geq 0$. Hence, it 
follows that

$$
\begin{aligned}
\left\|v_{n+1}-v_{n}\right\| & =\left\|\Pi_{C}\left(I-\alpha_{n+1} F\right) G\left(x_{n+1}\right)-\Pi_{C}\left(I-\alpha_{n} F\right) G\left(x_{n}\right)\right\| \\
& \leq\left\|\left(I-\alpha_{n+1} F\right) G\left(x_{n+1}\right)-\left(I-\alpha_{n} F\right) G\left(x_{n}\right)\right\| \\
& =\left\|G\left(x_{n+1}\right)-G\left(x_{n}\right)-\alpha_{n+1} F\left(G\left(x_{n+1}\right)\right)+\alpha_{n} F\left(G\left(x_{n}\right)\right)\right\| \\
& \leq\left\|G\left(x_{n+1}\right)-G\left(x_{n}\right)\right\|+\alpha_{n+1}\left\|F\left(G\left(x_{n+1}\right)\right)\right\|+\alpha_{n}\left\|F\left(G\left(x_{n}\right)\right)\right\| \\
& \leq\left\|x_{n+1}-x_{n}\right\|+\alpha_{n+1}\left\|F\left(G\left(x_{n+1}\right)\right)\right\|+\alpha_{n}\left\|F\left(G\left(x_{n}\right)\right)\right\|,
\end{aligned}
$$

which together with $\alpha_{n} \rightarrow 0$ and the boundedness of $\left\{F\left(G\left(x_{n}\right)\right)\right\}$ implies that

$$
\limsup _{n \rightarrow \infty}\left(\left\|v_{n+1}-v_{n}\right\|-\left\|x_{n+1}-x_{n}\right\|\right) \leq 0 .
$$

So, by Lemma 2.7 we get

$$
\lim _{n \rightarrow \infty}\left\|v_{n}-x_{n}\right\|=0
$$

Consequently,

$$
\lim _{n \rightarrow \infty}\left\|x_{n+1}-x_{n}\right\|=\lim _{n \rightarrow \infty}\left(1-\beta_{n}\right)\left\|v_{n}-x_{n}\right\|=0 .
$$

At the same time, we note that

$$
\begin{aligned}
\left\|v_{n}-G\left(x_{n}\right)\right\| & =\left\|\Pi_{C}\left(I-\alpha_{n} F\right) G\left(x_{n}\right)-G\left(x_{n}\right)\right\| \\
& =\left\|\Pi_{C}\left(I-\alpha_{n} F\right) G\left(x_{n}\right)-\Pi_{C} G\left(x_{n}\right)\right\| \\
& \leq \alpha_{n}\left\|F\left(G\left(x_{n}\right)\right)\right\| \\
& \rightarrow 0 .
\end{aligned}
$$

It follows from $\left\|v_{n}-x_{n}\right\| \rightarrow 0$ that

$$
\lim _{n \rightarrow \infty}\left\|x_{n}-G\left(x_{n}\right)\right\|=0 .
$$

Since $v_{n}=\Pi_{C}\left(I-\alpha_{n} F\right) G\left(x_{n}\right)$ for all $n \geq 0$, by Lemma 2.10 we have

$$
\begin{aligned}
\left\|v_{n}-G\left(v_{n}\right)\right\| & \leq\left\|v_{n}-x_{n}\right\|+\left\|x_{n}-G\left(x_{n}\right)\right\|+\left\|G\left(x_{n}\right)-G\left(v_{n}\right)\right\| \\
& \leq\left\|v_{n}-x_{n}\right\|+\left\|x_{n}-G\left(x_{n}\right)\right\|+\left\|x_{n}-v_{n}\right\| \\
& \leq 2\left\|v_{n}-x_{n}\right\|+\left\|x_{n}-G\left(x_{n}\right)\right\| \\
& \rightarrow 0 .
\end{aligned}
$$

Next, we show that

$$
\limsup _{n \rightarrow \infty}\left\langle F(\tilde{x}), J\left(\tilde{x}-v_{n}\right)\right\rangle \leq 0,
$$

where $\tilde{x} \in \Omega$ is the unique solution of VIP (3.21). 
To see this, we choose a subsequence $\left\{v_{n_{j}}\right\}$ of $\left\{v_{n}\right\}$ such that

$$
\limsup _{n \rightarrow \infty}\left\langle F(\tilde{x}), J\left(\tilde{x}-v_{n}\right)\right\rangle=\lim _{j \rightarrow \infty}\left\langle F(\tilde{x}), J\left(\tilde{x}-v_{n_{j}}\right)\right\rangle
$$

We may also assume that $v_{n_{j}} \rightarrow z \in C$. Note that $z \in \Omega$ in terms of Lemma 2.6 and (4.14). Therefore, it follows from VIP (3.21) and the weakly sequential continuity of $J$ that

$$
\limsup _{n \rightarrow \infty}\left\langle F(\tilde{x}), J\left(\tilde{x}-v_{n}\right)\right\rangle=\lim _{j \rightarrow \infty}\left\langle F(\tilde{x}), J\left(\tilde{x}-v_{n_{j}}\right)\right\rangle=\langle F(\tilde{x}), J(\tilde{x}-z)\rangle \leq 0 .
$$

Since $v_{n}=\Pi_{C}\left(I-\alpha_{n} F\right) G\left(x_{n}\right)$, according to Lemma 2.5, we have

$$
\left\langle\left(I-\alpha_{n} F\right) G\left(x_{n}\right)-\Pi_{C}\left(I-\alpha_{n} F\right) G\left(x_{n}\right), J\left(\tilde{x}-v_{n}\right)\right\rangle \leq 0 .
$$

From (4.16), we have

$$
\begin{aligned}
\| v_{n} & -\tilde{x} \|^{2} \\
& =\left\langle\Pi_{C}\left(I-\alpha_{n} F\right) G\left(x_{n}\right)-\tilde{x}, J\left(v_{n}-\tilde{x}\right)\right\rangle \\
& =\left\langle\Pi_{C}\left(I-\alpha_{n} F\right) G\left(x_{n}\right)-\left(I-\alpha_{n} F\right) G\left(x_{n}\right), J\left(v_{n}-\tilde{x}\right)\right\rangle+\left\langle\left(I-\alpha_{n} F\right) G\left(x_{n}\right)-\tilde{x}, J\left(v_{n}-\tilde{x}\right)\right\rangle \\
& \leq\left\langle\left(I-\alpha_{n} F\right) G\left(x_{n}\right)-\tilde{x}, J\left(v_{n}-\tilde{x}\right)\right\rangle \\
& =\left\langle\left(I-\alpha_{n} F\right) G\left(x_{n}\right)-\left(I-\alpha_{n} F\right) G(\tilde{x}), J\left(v_{n}-\tilde{x}\right)\right\rangle+\left\langle\left(I-\alpha_{n} F\right) \tilde{x}-\tilde{x}, J\left(v_{n}-\tilde{x}\right)\right\rangle \\
& \leq\left(1-\alpha_{n} \bar{\gamma}\right)\left\|x_{n}-\tilde{x}\right\|\left\|v_{n}-\tilde{x}\right\|+\alpha_{n}\left\langle F(\tilde{x}), J\left(\tilde{x}-v_{n}\right)\right\rangle \\
& \leq \frac{\left(1-\alpha_{n} \bar{\gamma}\right)^{2}}{2}\left\|x_{n}-\tilde{x}\right\|^{2}+\frac{1}{2}\left\|v_{n}-\tilde{x}\right\|^{2}+\alpha_{n}\left\langle F(\tilde{x}), J\left(\tilde{x}-v_{n}\right)\right\rangle .
\end{aligned}
$$

It follows that

$$
\begin{aligned}
\left\|v_{n}-\tilde{x}\right\|^{2} & \leq\left(1-\alpha_{n} \bar{\gamma}\right)^{2}\left\|x_{n}-\tilde{x}\right\|^{2}+2 \alpha_{n}\left\langle F(\tilde{x}), J\left(\tilde{x}-v_{n}\right)\right\rangle \\
& \leq\left(1-\alpha_{n} \bar{\gamma}\right)\left\|x_{n}-\tilde{x}\right\|^{2}+2 \alpha_{n}\left\langle F(\tilde{x}), J\left(\tilde{x}-v_{n}\right)\right\rangle .
\end{aligned}
$$

Finally, we prove that $x_{n} \rightarrow \tilde{x}$ as $n \rightarrow \infty$. From (4.12) and (4.17),

$$
\begin{aligned}
\left\|x_{n+1}-\tilde{x}\right\|^{2} \\
\quad \leq \beta_{n}\left\|x_{n}-\tilde{x}\right\|^{2}+\left(1-\beta_{n}\right)\left\|v_{n}-\tilde{x}\right\| \\
\quad \leq \beta_{n}\left\|x_{n}-\tilde{x}\right\|^{2}+\left(1-\beta_{n}\right)\left(1-\alpha_{n} \bar{\gamma}\right)\left\|x_{n}-\tilde{x}\right\|+2 \alpha_{n}\left(1-\beta_{n}\right)\left\langle F(\tilde{x}), J\left(\tilde{x}-v_{n}\right)\right\rangle \\
\quad=\left[1-\alpha_{n}\left(1-\beta_{n}\right) \bar{\gamma}\right]\left\|x_{n}-\tilde{x}\right\|+\alpha_{n}\left(1-\beta_{n}\right) \bar{\gamma}\left\{\frac{2}{\gamma}\left\langle F(\tilde{x}), J\left(\tilde{x}-v_{n}\right)\right\rangle\right\} .
\end{aligned}
$$

We apply Lemma 2.1 to the relation (4.18) and conclude that $x_{n} \rightarrow \tilde{x}$ as $n \rightarrow \infty$. This completes the proof. 
Authors' contributions

All authors contributed equally and significantly in writing this article. All authors read and approved the final manuscript.

\section{Author details}

${ }^{1}$ Department of Mathematics, King Abdulaziz University, P.O. Box 80203, Jeddah, 21589, Saudi Arabia. ${ }^{2}$ Center for Fundamental Science, Kaohsiung Medical University, Kaohsiung, 807, Taiwan.

\section{Acknowledgements}

This work was funded by the Deanship of Scientific Research (DSR), King Abdulaziz University under grant No. HiCi/15-130-1433. The authors, therefore, acknowledge with thanks DSR technical and financial support. The authors are thankful to the referees for their valuable suggestion/comments.

Received: 24 June 2013 Accepted: 3 September 2013 Published: 07 Nov 2013

\section{References}

1. Yao, Y, Liou, YC, Kang, SM, Yu, YL: Algorithms with strong convergence for a system of nonlinear variational inequalities in Banach spaces. Nonlinear Anal. 74(17), 6024-6034 (2011)

2. Ceng, LC, Wang, CY, Yao, JC: Strong convergence theorems by a relaxed extragradient method for a general system of variational inequalities. Math. Methods Oper. Res. 67, 375-390 (2008)

3. Korpelevich, GM: An extragradient method for finding saddle points and for other problems. Èkon. Mat. Metody 12 747-756 (1976)

4. Xu, HK: Viscosity approximation methods for nonexpansive mappings. J. Math. Anal. Appl. 298, $279-291$ (2004)

5. Mann, WR: Mean value methods in iteration. Proc. Am. Math. Soc. 4, 506-510 (1953)

6. Nadezhkina, N, Takahashi, W: Weak convergence theorem by an extragradient method for nonexpansive mappings and monotone mappings. J. Optim. Theory Appl. 128, 191-201 (2006)

7. Ceng, LC, Yao, JC: Relaxed and hybrid viscosity methods for general system of variational inequalities with split feasibility problem constraint. Fixed Point Theory Appl. 2013, 43 (2013)

8. Ceng, LC, Ansari, QH, Wong, MM, Yao, JC: Mann type hybrid extragradient method for variational inequalities, variational inclusions and fixed point problems. Fixed Point Theory 13, 403-422 (2012)

9. Sahu, DR, Wong, NC, Yao, JC: A unified hybrid iterative method for solving variational inequalities involving generalized pseudo-contractive mappings. SIAM J. Control Optim. 50, 2335-2354 (2012)

10. Ceng, LC, Guu, SM, Yao, JC: Weak convergence theorem by a modified extragradient method for variational inclusions,variational inequalities and fixed point problems. J. Nonlinear Convex Anal. 14, 21-31 (2013)

11. Xu, HK: Iterative algorithms for nonlinear operators. J. Lond. Math. Soc. 66, 240-256 (2002)

12. Xu, HK: Inequalities in Banach spaces with applications. Nonlinear Anal. 16, 1127-1138 (1991)

13. Reich, S: Weak convergence theorems for nonexpansive mappings in Banach spaces. J. Math. Anal. Appl. 67, 274-276 (1979)

14. Browder, FE: Convergence theorems for sequences of nonlinear operators in Banach spaces. Math. Z. 100, 201-225 (1967)

15. Suzuki, T: Strong convergence of Krasnoselskii and Mann's type sequences for one-parameter nonexpansive semigroups without Bochner integrals. J. Math. Anal. Appl. 305, 227-239 (2005)

10.1186/1687-1812-2013-258

Cite this article as: Latif et al.: Hybrid viscosity approximation methods for general systems of variational inequalities in Banach spaces. Fixed Point Theory and Applications 2013, 2013:258

\section{Submit your manuscript to a SpringerOpen ${ }^{\ominus}$ journal and benefit from:}

- Convenient online submission

- Rigorous peer review

- Immediate publication on acceptance

- Open access: articles freely available online

- High visibility within the field

- Retaining the copyright to your article 